\title{
Comparison of Mean Axial Length Measured by Acoustic Biometry versus Optical Biometry
}

\author{
Munira Shakir ${ }^{1}$, Ronak Afza ${ }^{2}$, Mariyam Azam ${ }^{3}$, Sahira Wasim ${ }^{4}$, Waqas Ali ${ }^{5}$ \\ ${ }^{1-5}$ Department of Ophthalmology, Liaquat National University Hospital, Karachi
}

\begin{abstract}
Purpose: To compare the mean axial length measured by acoustic biometry with optical biometry.

Design: Descriptive observational study.

Place and Duration of Study: Department of Ophthalmology Liaquat National Hospital and Medical College, Karachi from November 2018 to April 2019.

Methods: were 246 patients with visually significant cataract who were recruited in this study by consecutive sampling. Axial lengths were measured by non-contact optical method using Carl Zeiss IOL master. After instillation of local anesthetic, axial lengths were re-measured by contact method with A-Scan probe. All readings were taken by a single observer to avoid data collection bias. Mean and standard deviation was computed for quantitative variable i.e. age, axial length by Applanation ultra sound and axial length by optical biometry. Frequency and percentage was calculated for qualitative variables i.e. gender. Differences of axial length between the Applanation and optical biometry were compared by using pair T-test. Effect modifiers like age and gender were addressed through stratification, post stratification independent test for two groups and ANOVA for more than two groups was applied.
\end{abstract}

Results: The average age of the patients was $58.09 \pm 7.27$ years. Mean axial length by optical biometry was $23.744 \pm 0.74 \mathrm{~mm}$ as compared to $22.29 \pm 0.76 \mathrm{~mm}$ by acoustic method and this difference was statistically significant $(P=0.0005)$.

Conclusion: Results of axial length with Optical and acoustic biometry are significantly different with $p$ value less than 0.05. However, optical biometers fail in cases of dense media opacities where acoustic biometry in needed.

Key Words: Cataract, Axial length, Applanation ultrasound, Optical Biometry.

How to Cite this Article: Shakir M, Afza R, Azam M, Wasim S, Ali W. Comparison of Mean Axial Length Measured by Acoustic Biometry Versus Optical Biometry. Pak J Ophthalmol. 2021, 37 (3): 317-321.

Doi: $10.36351 /$ pjo.v37i3.1264

\section{INTRODUCTION}

Cataract surgery with intraocular lens (IOL) implantation is one of the most common and frequent surgical procedures performed in ophthalmology. ${ }^{1}$

Correspondence: Ronak Afza

Department of Ophthalmology, Liaquat National University Hospital, Karachi

Email: ronakafzamemon@yahoo.com

Received: May 03, 2021

Accepted: June 07, 2021
Now-a-days cataract surgery is also considered as a type of refractive surgery. ${ }^{2}$ Therefore, appropriate IOL power calculation is a crucial step to achieve the best possible refractive outcomes. ${ }^{3}$ Axial length and corneal curvatures are the two important parameters for IOL power calculation, among which axial length is the most important one. ${ }^{4}$ At present, biometry is done by two different methods, using distinct principles. One of these is A-scan contact ultrasound, which uses $10 \mathrm{MHZ}$ ultrasonic waves to measure axial length up to vitro-retinal interface only. It uses the echo delay time to measure intraocular distances. ${ }^{5}$ For accurate measurement 3 consecutive readings should 
be taken with a difference of $0.02 \mathrm{~m} .{ }^{6}$ Optical biometry (IOL Master)was introduced in 1999 by Carl Zeiss Meditec and uses the principle of partial coherence interferometry (PCI) with a 780nm laser diode infrared light and measures the axial length from tear film to retinal pigment epithelium. ${ }^{7}$ Advantages of this recent technology include high precision, its non-contact method and independency of observers bias. It is also useful in pseudophakic and silicone filled eyes. On the other hand, its limitations include media opacities like dense cataract and vitreous hemorrhage where ultrasound biometry is the method of choice.

A study conducted at King Saoud University showed that the mean axial length by IOL master was $23.7 \mathrm{~mm} \pm 0.5$ as compared to $23.6 \mathrm{~mm} \pm 0.6$ by acoustic method. This study showed that there was no statistically significant difference in the axial length measured by the two methods. ${ }^{6}$

The purpose of our study was to determine the mean axial length measured by Acoustic versus optical biometer and consequently find out whether there was difference between the two or not. This will help in refining post-operative refractive outcome by calculating the IOL power more accurately. Previous studies also indicate that the research on this subject has been scarce nationally as well internationally.

\section{METHODS}

The study was conducted in department of Ophthalmology, Liaquat National Hospital and Medical College, Karachi. It was a cross-sectional study of 6 months duration and was carried out between November 2018 to April 2019. By using open Epi, taking axial length of IOL master $=23.18 \pm 0.77^{3}$ axial length by Ultrasound $=22.94 \pm 0.75,{ }^{3}$ power of test $=80 \%$ and $95 \%$ confidence level, sample size was calculated. Mean difference equal to $00.24-0.02$ and margin of error of 0.0025 , the calculated sample size was 246 . It was non probability consecutive sampling. Inclusion criteria was age $40-80$ years, either gender with visually significant cataract (examined by slit lamp examination \& the best-corrected visual acuity of $<20 / 40$ or $6 / 12$ vision in the study eye on Snellen's chart). Patients with axial length between $22-25 \mathrm{~mm}$ were included. Patients with axial length less than $22 \mathrm{~mm}$ and greater than $25 \mathrm{~mm}$, dense cataract, history of previous refractive surgery, patients with corneal opacities or scars, corneal edema, keratoconus, keratoglobus, vitreous hemorrhage, retinal detachment or retinitis Pigmentosa and history of ocular trauma were excluded.

After the approval of study, all the consecutive patients fulfilling the inclusion criteria were recruited. Informed verbal consent was taken from all the patients. Procedure was explained to the patients thoroughly. Axial lengths were measured by noncontact optical method using Carl Zeiss IOL master. Then, after instillation of local anesthetic, Proparacaine, axial lengths were measured by contact method using A-Scan probe. To overcome the examiner bias, single researcher performed the measurements. Readings from both devices were compared and analyzed by using SPSS version 21 . Mean and standard deviation was computed for quantitative variable i.e. age, axial length by Applanation ultra sound and axial length by optical biometry. Frequency and percentage was calculated for qualitative variables i.e. gender. Differences of axial length between the Applanation and optical biometry were compared by using pair T-test. Effect modifiers like age and gender was addressed through stratification, post-stratification independent test for two groups and ANOVA for more than two groups was applied. P-value less than or equal to 0.05 was taken as significant.

\section{RESULTS}

There were 246 patients with visually significant cataract, who were recruited in this study. Most of the patients were 51 to 70 years of age. The average age of the patients was $58.09 \pm 7.27$ years. There were 112 $(45.53 \%)$ males and $134(54.47 \%)$ females. There were $102(41.46 \%)$ right and $144(58.54 \%)$ left eyes.

Table 1: Mean comparison of axial length with age group, gender and technique.

\begin{tabular}{llc}
\hline & Axial Length & P-value \\
\hline Age Group & & \\
41 - 50 Years & $0.14 \pm 0.14$ & \\
50 to 60 Years & $0.14 \pm 0.19$ & .572 \\
60 to 70 Years & $0.17 \pm 0.22$ & \\
$>$ 70 Years & $0.09 \pm 0.15$ & \\
Gender & & \\
Male & $0.17 \pm 0.25$ & 0.301 \\
Female & $0.14 \pm 1.4$ & \\
Technique & & \\
Applanation ultrasound & $22.29 \pm 0.76$ & $<0.0005$ \\
Optical Biometry & $23.44 \pm 0.74$ & \\
\hline
\end{tabular}

Independent t-test and ANOVA is applied

$* \mathrm{P}<0.05$ is considered as significant 
Mean axial length by optical biometry was $23.744 \pm$ $0.74 \mathrm{~mm}$ as compared to $22.29 \pm 0.76 \mathrm{~mm}$ by acoustic method. This difference was statistically significant (Difference $=0.153 \pm 0.197 ; \mathrm{P}=0.0005)$. Further detail is given in Table 1.

\section{DISCUSSION}

With an incidence of $53.7 \%$, cataract remains a significant ophthalmic morbidity where surgical treatment continues to be the definitive treatment and active area of research. ${ }^{8,9}$ An increasing number of technologies have been introduced over time to assist in biometric measurement of the eye, further enhancing refractive accuracy and precision as an achievable quality metric. Modern cataract surgery is considered a form of refractive surgery, aimed not only to restore visual clarity, but to provide excellent vision in refractive terms as well even when no intraocular lens (IOL) is implanted. When prescribed, an IOL is given to achieve a certain refractive status for the eye unlike what was obtainable in the past when refractive errors were corrected only after the surgery. This is made possible because of the development of modern, accurate diagnostic and surgical techniques. Biometry values can be obtained either by contact (Applanation), immersion or optical methods.

To determine the mean difference in axial length measured by Applanation ultrasound and optical biometry, a total 246 patients of either gender, age 4080 years with visually significant cataractwere recruited in this study. Most of the patients were 51 to 70 years of age and the average age of the patients was $58.09 \pm 7.27$ years. Most patients become aware of cataracts after the age of 60 . However, cataracts start developing much earlier than that in the form of dysfunctional Lens Syndrome in which the natural lens goes through a normal aging process, which may cause changes in vision from the age of 40 . In our study there were $112(45.53 \%)$ male and 134 (54.47\%) female.

It has been shown in Australian Blue Mountain Study that females are more associated with senile cataract and the findings of our study follow the same pattern. ${ }^{10}$ These findings are suggestive of female gender as a risk factor for cataract. ${ }^{11}$

Optical biometry offers many distinct advantages compared to acoustic biometry. It is a non-contact approach with accuracy and reproducibility in the context of non-severe pathology. When limitations such as dense media opacity, high axial myopia, and/or poor fixation prevent use of optical biometry, acoustic biometry becomes a useful alternative method, as it can be used in cases with significant media opacity. ${ }^{12,13}$ The advantage of the Applanation method is the faster measurements in the hands of a skilled operator. However, the disadvantage is the potential for corneal compression that may result in shorter axial length measurements. The disadvantage of the first optical biometery (e.g. IOL Master) in common clinical use, was the inaccurate measurement in cases of media opacities such as corneal scar and vitreous hemorrhage.

In this study, we found statistically significant difference between the results of two methods. ( $\mathrm{P}=$ 0.0005). However, in a previous study, no statistically significant difference was seen between the two methods for myopic eyes. ${ }^{14}$ Similarly Henessy et al, ${ }^{15}$ reported that there was longer measurement by contact method as compared to immersion technique. They also suggested that repeating measurements made contact ultrasound biometry comparable to that of immersion with no clinically significant difference in mean axial lengths.

In a recent local study, comparison between axial length measured with non-contact and ultrasound technique showed that there was statistically significant difference $(p<0.05)$ between the two. ${ }^{16}$ Inone study, the precision achieved with optical biometry was equal to acoustic biometry. ${ }^{17}$

Another researcher observed significant underestimation of axial length measurement when using the IOL master in eyes with rhegmatogenous retinal detachment with macular involvement, which could affect IOL power selection. ${ }^{18}$

In an Indian study, Applanation biometry with acoustic method showed significantly smaller axial lengths as compared to the optical biometry. ${ }^{19}$ In contrast to this, Kaswin, et al, compared the performance of acoustic Scan with IOL- Master 500 in 50 eyes and reported excellent correlation in the axial lengths obtained by the 2 devices when the axial length was in the range of $22-27 \mathrm{~mm} .^{20}$

Limitation of this study is that we did not consider the other factors which affect the biometry, the most important of which is the keratometry. The effect on the final intraocular lens power calculation was also not taken into account. Only a single formula SRK/T 
was used. Further research to address these issues is required to bring the results of biometry closer to emmetropia.

\section{CONCLUSION}

Results of axial length with Optical and acoustic biometry are significantly different with $\mathrm{p}$ value less than 0.05. However, optical biometers fail in cases of dense media opacities where acoustic biometry in needed. Ophthalmologist must keep ultrasound biometry in hand for patients whosebiometry cannot be done with optical device use to density of the cataract.

\section{Ethical Approval}

The study was approved by the Institutional review board/ Ethical review board.

(Ref: App 0450-2018-LNH-ERC)

\section{Conflict of Interest}

Authors declared no conflict of interest.

\section{REFRENCES}

1. Zocher MT, Rozema JJ, Oertel N, Dawczynski J, Wiedemann P, Rauscher FG, et al. Biometry and visual function of a healthy cohort in Leipzig, Germany. BMC Ophthalmol. 2016; 16: 79.

2. Chen M. Refractive cataract surgery - what we were, what we are, and what we will be: A personal experience and perspective. Taiwan J Ophthalmol. 2019; 9 (1): 1-3. Doi: 10.4103/tjo.tjo_133_18.

3. Behndig A, Montan P, Stenevi U, Kugelberg M, Zetterström C, Lundström M, et al. Aiming for emmetropia after cataract surgery: Swedish national cataract register study. J Cataract Refract Surg. 2012; 38: 1181-1186.

4. Wissa AR, Wahba SS, Roshdy MM. Agreement and relationship between ultrasonic and partial coherence interferometry measurements of axial length and anterior chamber depth. Clinic Ophthalmol. 2012; 6: 193.

5. Moshirfar M, Buckner B, Ronquillo YC, Hofstedt D. Biometry in cataract surgery: a review of the current literature. Curr Opin Ophthalmol. 2019; 30 (1): 9-12. Doi: 10.1097/ICU.0000000000000536.

6. Nakhli FR. Comparison of optical biometry and Applanation ultrasound measurements of the axial length of the eye. Saudi J Ophthalmol. 2014; 28 (4): 287-291.
7. Huang J, Savini G, Li J, Lu W, Wu F, Wang J, et al. Evaluation of a new optical biometry device for measurements of ocular components and its comparison with IOL Master. Br J Ophthalmol. 2014; 98 (9): 1277 1281.

8. Klein BE, Klein R, Lee KE. Incidence of age-related cataract over a 10-year interval: the Beaver Dam Eye Study. Ophthalmology, 2002; 109 (11): 2052-2057.

9. Congdon N, Vingerling JR, Klein BE, West S, Friedman DS, Kempen J, et al. Prevalence of cataract and pseudophakia/aphakia among adults in the United States. Arch Ophthalmol. 2004; 122 (4): 487-494.

10. Cumming RG, Michel P. Hormone replacement therapy, reproductive factors and cataract. The Blue Mountain Eye Study. Am J Epidemiol. 1997; 145: 242249.

11. Michel P, Cumming RG, Attebo K, Panchapakesan J. Prevalence of cataract in Australia. The Blue Mountain Eye Study, Ophthalmology, 1997; 104: 581588.

12. Verhulst E, Vrijghem JC. Accuracy of intraocular lens power calculations using the Zeiss IOL master. A prospective study. Bull Soc Belge Ophtalmol. 2001; 281 (281): 61-65.

13. Goebels SC, Seitz B, Langenbucher A. Comparison of the new biometer OA-1000 with IOL Master and Tomey AL-3000. Curr Eye Res. 2013; 38 (9): 910-916.

14. Wang XG, Dong J, Pu YL, Liu HJ, Wu Q. Comparison axial length measurements from three biometric instruments in high myopia. Int $\mathbf{J}$ Ophthalmol. 2016; 9 (6): 876.

15. Hennessy MP, Franzco DG. Contact versus immersion biometry of axial length before cataract surgery. J Cataract Refract Surg. 2003; 29: 2195-2198.

16. Ashraf MA, Sarwar MS, Afzal MA, Khalid I, Shahid S. Comparison of Axial Ocular Measurements with Contact and Non-Contact Biometry, Pak J Ophthalmol. 2020; 36 (1): 72-78.

DOI: https://doi.org/10.36351/pjo.v36i1.922.

17. Tappeiner C, Rohrer K, Frueh BE, Waelti R, Goldblum D. Clinical comparison of biometry using the non-contact optical low coherence reflectometer (Lenstar LS 900) and contact ultrasound Biometer (Tomey AL-3000) in cataract eyes. Br J Ophthalmol. 2010; 94 (5): 666-667.

18. Pongsachareonnont $\mathbf{P}$, Tangjanyatam $\mathbf{S}$. Accuracy of axial length measurements obtained by optical biometry and acoustic biometry in rhegmatogenous retinal detachment: a prospective study. Clin Ophthalmol. 2018; 12: 973-980. https://doi.org/10.2147/OPTH.S165875

19. Chandra M, Jitendra S, Chandra AM, Singh Indian TG. The comparative study of applanation and optical coherence biometry methods for the intra ocular lens power calculation. J. Pharm. Biol. Res. 2018; 6 (3): 1-8. 
20. Kaswin G, Rousseau A, Mgarrech M, Barreau E, Labetoulle M. Biometry and intraocular lens power calculation results with a new optical biometry device: Comparison with the gold standard. J Cataract Refract Surg. 2014; 40: 593-600.

\section{Authors' Designation and Contribution}

Munira Shakir; Professor: Concepts, Manuscript editing, Manuscript review.
Ronak Afza; Resident: Design, Literature search, Data acquisition, Manuscript review.

Mariyam Azam; Resident: Data acquisition, Data analysis, Manuscript review.

Sahira Wasim; Resident: Statistical analysis, Manuscript preparation, $v$

Waqas Ali; Resident: Statistical analysis, Manuscript preparation, Manuscript review. 